\title{
A produção científica da Psicologia brasileira acerca do desemprego*
}

\section{The scientific production of Brazilian Psychology about unemployment}

Recibido: marzo 4 de 2013 | Revisado: agosto 1 de 2013 | Aceptado: septiembre 15 de 2013

\author{
Fellipe Coelho-Lima ** \\ Ana Ludmila Freire Costa *** \\ PEDRO F. BENDASSOLLI ***** \\ Universidade Federal do Rio Grande do Norte,
}

Brasil

Doi: $10.11144 / J a v e r i a n a . U P S Y 12-4 . p c p b$

Para citar este artículo: Coelho-Lima, F., Costa, A. L. F., \& Bendassolli, P. F. (2013). A produção científica da Psicologia brasileira acerca do desemprego. Universitas Psychologica, 12(4), 1283-1299. Doi: 10.11144/Javeriana.UPSY12-4.pcpb

* Artigo de investigação.

*** E-mail: fellipecoelholima@gmail.com

*** E-mail: analudmila@gmail.com

***mail: pbendassolli@gmail.com

\section{RES UMO}

Objetivou-se caracterizar a produção científica da Psicologia brasileira sobre desemprego. Foram coletados artigos, dissertações e teses (58), analisados cientométrica e tematicamente. Os documentos foram publicados de 1987 a 2012, por 46 primeiros-autores, predominando trabalhos empíricos (74.1\%). Os temas mais estudados foram: saúde mental (43.1\%), contexto social (22.4\%) e estratégias de enfrentamento do desemprego (20.7\%). As contribuições das pesquisas relacionam-se a intervenções (47\%) e avanços teóricos (40\%), seja para a Psicologia (28.2\%), compreensão do desemprego (23\%) ou melhoria de serviços e políticas (20.5\%). Concluí-se que a Psicologia brasileira trata do desemprego a partir da saúde mental e características do desempregado, e investigando elementos sociais ligados ao desemprego. É necessária variação temática e metodológica, priorizando-se uma perspectiva política de emancipação dos trabalhadores.

Palavras-chave autores

Desemprego, produção científica, psicologia social crítica.

Palavras-chave descriptores

Psicología social, Cienciometría, Brasil.

\section{RESUMEN}

El objetivo del presente estudio fue caracterizar la producción científica de la Psicología brasileña acerca del desempleo. Se han recogido artículos, disertaciones y tesis, analizados cientométrica y temáticamente y publicados entre 1987 y 2012, prevaleciendo los trabajos empíricos. Los temas más estudiados fueron: salud mental, contexto social y estrategias de enfrentamiento del desempleo. Las contribuciones de las investigaciones se relacionan con intervenciones y avances teóricos, para la Psicología, la comprensión del desempleo o la mejoría de servicios y políticas. Se concluye que la Psicología brasileña aborda el desempleo a partir de la salud mental y de las características del desempleado, investigando elementos sociales del desempleo. Se hace necesaria una variación temática y metodológica que priorice una perspectiva política de emancipación de los trabajadores.

Palabras clave autores

Desempleo, producción científica, psicología social crítica.

Palabras clave descriptores

Psicología social, Cienciometría, Brasil. 
O desemprego apresenta-se como um dos grandes problemas a ser enfrentado pelas diversas nações atualmente. Longe de ser um fenômeno inédito, trata-se de uma estrutura funcional ao modo de produção capitalista $^{1}$ (Harvey, 2010). Na América Latina, por exemplo, ainda que nos últimos anos os índices de desemprego estejam diminuindo, em 2012, 4.7\% da população, ou aproximadamente 27 milhões de trabalhadores com mais de 25 anos nesses países, encontrava-se desempregada (Organización Internacional del Trabajo [OIT], 2012). Especificamente no Brasil, segundo a OIT (2012), as cifras chegam a oito milhões de desempregados, representando 4\% da população brasileira.

Para compreender tal fenômeno, diversas disciplinas têm se dedicado a estudos sobre as causas e as formas de manifestação e enfrentamento do desemprego. A Psicologia não se absteve dessa tarefa, sobretudo a Psicologia Social Crítica (Bendassolli, 2009), que concebe o ser humano constituído, ontologicamente e subjetivamente, a partir do trabalho e da linguagem, bem como de seu entorno social e histórico (González Rey, 2004; Lane, 1989).

No cenário mundial, os estudos da Psicologia acerca do desemprego datam do século passado. De maneira geral, esses estudos foram influenciados pelos próprios ciclos das crises capitalistas, nas quais os índices de desemprego se agravaram, como se percebe após a crise de 1929 e de 1970 (Cascio \& Aguinis, 2008). Em particular, merecem destaque três abordagens teóricas clássicas sobre desemprego.

A primeira corresponde à teoria dos estágios, que propõe que as pessoas se movem em distintos estágios de respostas à sua situação de desemprego — e.g. Beales e Lambert (1934) e Zawadzki e

1 Unidades de produção capitalistas vivem uma relação contraditória e dialética com a força de trabalho: para a ampliação da reprodução do capital dentro do processo produtivo é necessário que haja um dispêndio de trabalho por parte dos trabalhadores, o qual, ao mesmo tempo, significa um custo para essa produção. Se por um lado é pela extração de mais-valia — oriunda do trabalho excedente dos trabalhadores - que o capitalista obtém o lucro e consequentemente o reaplica na produção em forma de capital, a variação no quanto se gasta na contratação da força de trabalho também determina a amplitude da mais-valia extraída (Marx, 1867/2010).
Lazarsfeld (1935). Essa teoria está organizada em três momentos: choque seguido de busca por novo emprego; elaboração de atitudes pessimistas associadas à vivência de estresse e ansiedade; e atitude fatalista e de resignação. Como aponta Feather (1990), essa teoria é criticada pela simplificação do fenômeno do desemprego a estágios e é progressivamente substituída por outras, especialmente pelas teorias sobre processos de enfrentamento (coping).

A segunda abordagem, proposta por Jahoda $(1979,1982)$, é a funcionalista, a qual se baseia no reconhecimento das funções manifestas (marcadas pelas consequências da perda da remuneração) e latentes (como a organização da identidade, a percepção e a estruturação do tempo, o senso de ser ativo, dentre outros aspectos subjetivos). Embora sujeita a muitas críticas, essa teoria, por vezes chamada de "teoria da privação", segue, ainda hoje, como importante referência sobre o assunto.

Uma terceira abordagem que emergiu no decorrer dos anos 1980 é o modelo vitamínico proposto por Warr (1987), a qual aponta o desemprego com uma situação de privação, para o indivíduo, de elementos fundamentais para a manutenção de sua saúde mental, como: oportunidade de controle e de uso de suas próprias habilidades, segurança física, contato com outras pessoas, posição social valorizada.

Essas teorias, e outras que surgiram entre 1930 e 1980, revelam que os esforços da Psicologia ante o fenômeno do desemprego concentraram-se, sobretudo, em evidenciar seus efeitos sobre a dimensão afetiva e comportamental dos desempregados, abordando tópicos como rompimento da identidade social, emergência de quadros depressivos e redução da satisfação com a vida (Álvaro, 1992; Bendassolli, 2009; Feather, 1990; Pérez, 2007). Em especial na América Latina, além dos tópicos já citados, a produção concentrou-se na identificação de relações entre as características e os comportamentos dos desempregados e a permanência destes na situação de desemprego (Pérez, 2007). Essas mesmas tendências se mantiveram no cenário latino-americano anos mais tarde, nos anos 1990 
e seguintes, como exemplificado nas pesquisas de Carlotto e Gobbi (2001), Gómez, Morejó e Sabater (2008), Iribarría, Ruiz, Pardo e Martín (2002) e Pérez (2007).

No caso brasileiro, pesquisas têm apontado para uma crescente preocupação da Psicologia com o desemprego (Borges-Andrade \& Pagotto, 2010; Campos, Duarte, Cezar, \& Pereira, 2011; Leal, Aguillera, \& Melo-Silva, 2011). A despeito de tal constatação, ainda não se tem conhecimento detalhado a respeito desses trabalhos. Assim, os dados sobre a estrutura de produção e circulação da referida produção ainda carecem de análises (por exemplo, nome e localização de autores e instituições que se dedicam a essa problemática, veículos utilizados para divulgação dos documentos, bem como os tópicos privilegiados).

De acordo com Santos e Kobashi (2009), a identificação de padrões de produção científica e de distribuição desta, assim como o mapeamento de perspectivas metodológicas e temáticas abordadas, ajuda a definir lacunas e promover avanços em determinados campos de pesquisa. Por esse motivo, questiona-se: quais são e como têm sido empreendidos os estudos científicos brasileiros sobre o desemprego a partir da perspectiva da Psicologia? Assim, objetiva-se, com esta pesquisa, caracterizar a produção científica da Psicologia a respeito do desemprego no Brasil, em seus aspectos cientométricos, metodológicos e temáticos, a fim de indicar limites e desafios para esse campo de estudos.

\section{Método}

A fim de alcançar o objetivo proposto, levantou-se a produção científica em Psicologia sobre a questão do desemprego condensada em artigos, dissertações e teses. Foram utilizados, como descritores de busca, as palavras-chaves "psicólogo" e "Psicologia", associadas com "desemprego" e "desempregado". As bases utilizadas foram Scientific Eletronic Library Online (SciELO), Literatura Latino-Americana e do Caribe em Ciências da Saúde (Lilacs) e Periódicos Eletrônicos em Psicologia (PEPsic), tanto por meio da visita aos sítios eletrônicos dessas bases de dados como pela Biblioteca Virtual em Saúde - Psicologia (BVS-PSI), pela Biblioteca Digital Brasileira de Teses e Dissertações do Instituto Brasileiro de Informação em Ciência e Tecnologia (BDTD/IBICT), pelo Banco de Teses da Coordenação de Aperfeiçoamento de Pessoal de Nível Superior (Capes) e pelos arquivos dos periódicos científicos Cadernos de Psicologia Social do Trabalho, Revista Psicologia: Organizações e Trabalho e Psicologia \& Sociedade.

O levantamento abarcou publicações veiculadas nos últimos 25 anos - apesar de não ter havido demarcação prévia do período de publicação do material, o primeiro trabalho identificado é de 1987 e o último, de 2012. A decisão pela inclusão do material foi realizada com base nos resumos, sendo excluídos aqueles que apenas tangenciavam o tema do desemprego (por exemplo, os textos que citam o desemprego para caracterizar o contexto social de ocorrência de outro fenômeno que é o foco principal do estudo, como a violência), bem como os que estavam em outros formatos que não artigos, dissertações e teses (como livros, capítulos de livros, relatórios de pesquisa, resumos e artigos em anais de congresso). A recuperação desse material ocorreu no final do primeiro semestre de 2012, tendo sido obtidos 58 produções, cujos textos integrais estão publicados no idioma português.

Os manuscritos foram analisados de acordo com três dimensões, cada qual contendo um conjunto de itens cujos dados foram extraídos de três fontes, como apresentado na Tabela 1.

No caso dos itens obtidos pelos resumos, realizou-se uma leitura exaustiva dos textos a fim de construir categorias que organizassem as informações. Excetua-se desse procedimento o item delineamento dos estudos, que foi embasado em Sampieri, Collado e Lucio (2006). Todos os itens foram compilados em planilha eletrônica, com base na qual foi possível realizar análises descritivas e comparativas. A Tabela 2 apresenta a lista com todos os materiais analisados por esta pesquisa e evidencia o aspecto estudado, o tipo de estudo e a população consultada em cada trabalho. 
TABELA 1

Dimensões e itens analisados nos documentos coletados

\begin{tabular}{cll}
\hline \multirow{2}{*}{ Dimensão } & \multicolumn{1}{c}{ Item } & \multicolumn{1}{c}{ Fonte dos dados } \\
\hline \multirow{2}{*}{ Cientométrica } & $\begin{array}{l}\text { Tipo de documento } \\
\text { Década da publicação }\end{array}$ & $\begin{array}{l}\text { Metadados dos bancos de } \\
\text { dados }\end{array}$ \\
\cline { 2 - 3 } & $\begin{array}{l}\text { Vinculação institucional do primeiro autor } \\
\text { Projetos e linhas de pesquisa do primeiro autor }\end{array}$ & Currículo Lattes \\
\hline \multirow{2}{*}{ Metodológica } & Tipo de pesquisa & Delineamento de pesquisa dos estudos \\
& Parcela da população investigadaa & Resumo \\
\hline \multirow{2}{*}{ Temática } & Aspectos do desemprego abordados & \\
& Tipo da contribuição do estudo declarado pelos autores & Resumo \\
\hline
\end{tabular}

a. Esses itens apenas foram investigados quando os estudos eram classificados como relatos de pesquisa no item delineamento de pesquisa dos estudos.

Fonte: Pesquisa direta.

TABELA 2

Lista de documentos analisados

\begin{tabular}{|c|c|c|c|}
\hline Documento & Aspecto estudado & Tipo de estudo & População \\
\hline $\begin{array}{l}\text { Ackermann } \\
(2007)\end{array}$ & $\begin{array}{l}\text { Contexto social do desempregado (mercado } \\
\text { de trabalho) }\end{array}$ & $\begin{array}{l}\text { Relato de pesquisa } \\
\text { (descritivo) }\end{array}$ & Categoria profissional \\
\hline $\begin{array}{l}\text { Ackermann et al. } \\
(2005)\end{array}$ & $\begin{array}{l}\text { Saúde mental (sofrimento psíquico e/ou as- } \\
\text { pectos subjetivos) }\end{array}$ & $\begin{array}{l}\text { Relato de pesquisa } \\
\text { (comparativo) }\end{array}$ & Desempregados em geral \\
\hline $\begin{array}{l}\text { Araújo, Montei- } \\
\text { ro, Lima e Souza } \\
\text { (2006) }\end{array}$ & Atuação do psicólogo (projeto de extensão) & Relato de experiência & Desempregados em geral \\
\hline Argolo (2001) & Saúde mental (bem-estar psicológico) & $\begin{array}{l}\text { Relato de pesquisa (ex- } \\
\text { plicativo) }\end{array}$ & Desempregados em geral \\
\hline $\begin{array}{l}\text { Argolo e Araújo } \\
\text { (2004) }\end{array}$ & Saúde mental (bem-estar psicológico) & $\begin{array}{l}\text { Relato de pesquisa (ex- } \\
\text { plicativo) }\end{array}$ & Desempregados em geral \\
\hline $\begin{array}{l}\text { Azevedo et al. } \\
(1998)\end{array}$ & $\begin{array}{l}\text { Enfrentamento do desemprego (busca de tra- } \\
\text { balho e sobrevivência) }\end{array}$ & $\begin{array}{l}\text { Relato de pesquisa } \\
\text { (descritivo) }\end{array}$ & $\begin{array}{l}\text { Vinculada a programas de } \\
\text { apoio ao desempregado }\end{array}$ \\
\hline Baccaro (1987) & $\begin{array}{l}\text { Atributos pessoais dos desempregados (habili- } \\
\text { dades pessoais) }\end{array}$ & $\begin{array}{l}\text { Relato de pesquisa (ex- } \\
\text { ploratório) }\end{array}$ & - \\
\hline $\begin{array}{l}\text { Barros e Oliveira } \\
(2009)\end{array}$ & $\begin{array}{l}\text { Saúde mental (sofrimento psíquico e/ou as- } \\
\text { pectos subjetivos) }\end{array}$ & $\begin{array}{l}\text { Relato de pesquisa } \\
\text { (comparativo) }\end{array}$ & Desempregados em geral \\
\hline Batista (2005) & $\begin{array}{l}\text { Enfrentamento do desemprego (busca de tra- } \\
\text { balho e sobrevivência) }\end{array}$ & $\begin{array}{l}\text { Relato de pesquisa } \\
\text { (descritivo) }\end{array}$ & Desempregados em geral \\
\hline $\begin{array}{l}\text { Bezerra-Ribeiro } \\
(2008)\end{array}$ & $\begin{array}{l}\text { Saúde mental (uso de drogas), contexto social } \\
\text { do desempregado (suporte social) }\end{array}$ & $\begin{array}{l}\text { Relato de pesquisa } \\
\text { (comparativo) }\end{array}$ & Desempregados em geral \\
\hline Borcsik (2006) & $\begin{array}{l}\text { Saúde mental (ansiedade), enfrentamento } \\
\text { do desemprego (busca de trabalho e sobrevi- } \\
\text { vência) }\end{array}$ & $\begin{array}{l}\text { Relato de pesquisa } \\
\text { (comparativo) }\end{array}$ & Categoria profissional \\
\hline Botthcer (2012) & $\begin{array}{l}\text { Saúde mental (estresse), atributos pessoais } \\
\text { dos desempregados (habilidades sociais) }\end{array}$ & $\begin{array}{l}\text { Relato de pesquisa } \\
\text { (comparativo) }\end{array}$ & Categoria profissional \\
\hline
\end{tabular}




\begin{tabular}{|c|c|c|c|}
\hline Brandão (2003) & $\begin{array}{l}\text { Saúde mental (sofrimento psíquico e/ou as- } \\
\text { pectos subjetivos), enfrentamento do desem- } \\
\text { prego (busca de trabalho e sobrevivência), } \\
\text { contexto social do desempregado (discurso da } \\
\text { qualificação profissional) }\end{array}$ & $\begin{array}{l}\text { Relato de pesquisa (ex- } \\
\text { plicativo) }\end{array}$ & Categoria profissional \\
\hline Caldana (2000) & $\begin{array}{l}\text { Saúde mental (qualidade de vida), enfrentamento } \\
\text { do desemprego (busca de trabalho e sobrevivência) }\end{array}$ & $\begin{array}{l}\text { Relato de pesquisa (ex- } \\
\text { ploratório) }\end{array}$ & $\begin{array}{l}\text { Vinculada a programas de } \\
\text { apoio ao desempregado }\end{array}$ \\
\hline Campos (2011) & $\begin{array}{l}\text { Saúde mental (sofrimento psíquico e/ou as- } \\
\text { pectos subjetivos) }\end{array}$ & $\begin{array}{l}\text { Relato de pesquisa } \\
\text { (comparativo) }\end{array}$ & $\begin{array}{l}\text { Vinculada a programas de } \\
\text { apoio ao desempregado }\end{array}$ \\
\hline Cardoso (2004) & $\begin{array}{l}\text { Saúde mental (sofrimento psíquico e/ou as- } \\
\text { pectos subjetivos) }\end{array}$ & $\begin{array}{l}\text { Relato de pesquisa } \\
\text { (descritivo) }\end{array}$ & $\begin{array}{l}\text { Vinculada a programas de } \\
\text { apoio ao desempregado }\end{array}$ \\
\hline $\begin{array}{l}\text { Carlotto, Gob- } \\
\text { bi e Reichert } \\
\text { (2001) }\end{array}$ & $\begin{array}{l}\text { Atributos pessoais dos desempregados (habili- } \\
\text { dades sociais) }\end{array}$ & Relato de experiência & $\begin{array}{l}\text { Temporalidade do desem- } \\
\text { prego }\end{array}$ \\
\hline $\begin{array}{l}\text { Castelhano } \\
(2005)\end{array}$ & Saúde mental (medo do desemprego) & $\begin{array}{l}\text { Ensaio teórico (articu- } \\
\text { lação e problematização } \\
\text { de construtos teóricos) }\end{array}$ & 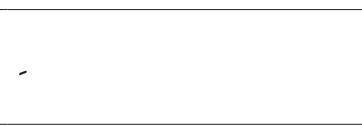 \\
\hline $\begin{array}{l}\text { Castelhano } \\
(2006)\end{array}$ & $\begin{array}{l}\text { ú́de mental (sofrimento psíquico e/ou as- } \\
\text { ctos subjetivos) }\end{array}$ & $\begin{array}{l}\text { Relato de pesquisa (ex- } \\
\text { ploratório) }\end{array}$ & $\begin{array}{l}\text { Vinculada a } \\
\text { apoio ao des }\end{array}$ \\
\hline Coêlho (2007) & $\begin{array}{l}\text { Atributos pessoais dos desempregados (habili- } \\
\text { dades pessoais) }\end{array}$ & $\begin{array}{l}\text { Relato de pesquisa } \\
\text { (comparativo) }\end{array}$ & $\begin{array}{l}\text { Vinculada a } \\
\text { apoio ao deser }\end{array}$ \\
\hline Costa (2005) & $\begin{array}{l}\text { Contexto social do desempregado (discurso da } \\
\text { qualificação profissional), enfrentamento do } \\
\text { desemprego (busca de trabalho e sobrevivência) }\end{array}$ & $\begin{array}{l}\text { Relato de pesquisa } \\
\text { (descritivo) }\end{array}$ & Desempregados em geral \\
\hline Cruz (2008) & Atuação do psicólogo (profissional) & $\begin{array}{l}\text { Relato de pesquisa (ex- } \\
\text { ploratório) }\end{array}$ & $\begin{array}{l}\text { Psicólogos que trabalham } \\
\text { com desemprego }\end{array}$ \\
\hline $\begin{array}{l}\text { Cruz e Monteiro } \\
(2010)\end{array}$ & Atuação do psicólogo (profissional) & $\begin{array}{l}\text { Relato de pesquisa (ex- } \\
\text { ploratório) }\end{array}$ & $\begin{array}{l}\text { Psicólogos que trabalham } \\
\text { com desemprego }\end{array}$ \\
\hline $\begin{array}{l}\text { Diogo e } \\
\text { Coutinho (2006) }\end{array}$ & Contexto social do desempregado (gênero) & $\begin{array}{l}\text { Ensaio teórico (articu- } \\
\text { lação e problematização } \\
\text { de construtos teóricos) }\end{array}$ & 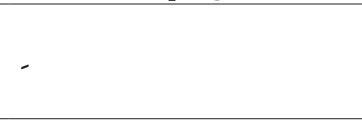 \\
\hline $\begin{array}{l}\text { Farina e Neves } \\
(2007)\end{array}$ & $\begin{array}{l}\text { Valores sociais relacionados ao desemprego } \\
\text { (interpretações acerca do desemprego), en- } \\
\text { frentamento do desemprego (busca de trabal- } \\
\text { ho e sobrevivência) }\end{array}$ & Relato de experiência & $\begin{array}{l}\text { Vinculada a programas de } \\
\text { apoio ao desempregado }\end{array}$ \\
\hline Felisberto (2001) & $\begin{array}{l}\text { Contexto social do desempregado (discurso } \\
\text { da qualificação profissional) }\end{array}$ & $\begin{array}{l}\text { Relato de pesquisa } \\
\text { (comparativo) }\end{array}$ & Escolaridade \\
\hline Freitas (2000) & $\begin{array}{l}\text { Saúde mental (sofrimento psíquico e/ou as- } \\
\text { pectos subjetivos), enfrentamento do desem- } \\
\text { prego (busca de trabalho e sobrevivência) }\end{array}$ & $\begin{array}{l}\text { Relato de pesquisa (ex- } \\
\text { plicativo) }\end{array}$ & Categoria profissional \\
\hline $\begin{array}{l}\text { Garrido, Paiva, } \\
\text { Nascimento, } \\
\text { Sousa e Santos } \\
(2007)\end{array}$ & $\begin{array}{l}\text { Valores sociais relacionados ao desemprego } \\
\text { (estigma e discriminação) }\end{array}$ & $\begin{array}{l}\text { Relato de pesquisa (ex- } \\
\text { plicativo) }\end{array}$ & $\begin{array}{l}\text { Vinculada a programas de } \\
\text { apoio ao desempregado }\end{array}$ \\
\hline $\begin{array}{l}\text { Gondim, Almei- } \\
\text { da, Pena e Fil- } \\
\text { gueiras (2001) }\end{array}$ & Atuação do psicólogo (projeto de extensão) & Relato de experiência & - \\
\hline Goulart (2003) & $\begin{array}{l}\text { Enfrentamento do desemprego (movimento } \\
\text { social) }\end{array}$ & $\begin{array}{l}\text { Relato de pesquisa } \\
\text { (comparativo) }\end{array}$ & $\begin{array}{l}\text { Vinculada a programas de } \\
\text { apoio ao desempregado }\end{array}$ \\
\hline Guilland (2010) & $\begin{array}{l}\text { Atributos pessoais dos desempregados (ha- } \\
\text { bilidades sociais), saúde mental (bem-estar } \\
\text { psicológico) }\end{array}$ & $\begin{array}{l}\text { Relato de pesquisa } \\
\text { (comparativo) }\end{array}$ & $\begin{array}{l}\text { Vinculada a programas de } \\
\text { apoio ao desempregado }\end{array}$ \\
\hline $\begin{array}{l}\text { Guilland e Mon- } \\
\text { teiro (2010a) }\end{array}$ & $\begin{array}{l}\text { Valores sociais relacionados ao desemprego } \\
\text { (atribuição de causalidade), saúde mental (so- } \\
\text { frimento psíquico e/ou aspectos subjetivos), } \\
\text { contexto social do desempregado (conjuntura } \\
\text { socioeconômica) }\end{array}$ & $\begin{array}{l}\text { Relato de pesquisa (ex- } \\
\text { ploratório) }\end{array}$ & - \\
\hline
\end{tabular}




\begin{tabular}{|c|c|c|c|}
\hline $\begin{array}{l}\text { Guilland e Mon- } \\
\text { teiro }(2010 \mathrm{~b})\end{array}$ & $\begin{array}{l}\text { Atributos pessoais dos desempregados (ha- } \\
\text { bilidades sociais), saúde mental (bem-estar } \\
\text { psicológico) }\end{array}$ & $\begin{array}{l}\text { Relato de pesquisa } \\
\text { (comparativo) }\end{array}$ & $\begin{array}{l}\text { Vinculada a programas de } \\
\text { apoio ao desempregado }\end{array}$ \\
\hline $\begin{array}{l}\text { Mandelbaum } \\
(2004)\end{array}$ & $\begin{array}{l}\text { Atuação do psicólogo (projeto de extensão), } \\
\text { saúde mental (sofrimento psíquico e/ou as- } \\
\text { pectos subjetivos) }\end{array}$ & $\begin{array}{l}\text { Relato de pesquisa (ex- } \\
\text { plicativo) }\end{array}$ & Desempregados em geral \\
\hline $\begin{array}{l}\text { Monteiro, Pesen- } \\
\text { ti, Maus, Botte- } \\
\text { ga e Machado } \\
(2008)\end{array}$ & Atuação do psicólogo (projeto de extensão) & Relato de experiência & - \\
\hline Neves (2006) & $\begin{array}{l}\text { Contexto social do desempregado (mercado } \\
\text { de trabalho) }\end{array}$ & $\begin{array}{l}\text { Ensaio teórico (articu- } \\
\text { lação e problematização } \\
\text { de construtos teóricos) }\end{array}$ & - \\
\hline $\begin{array}{l}\text { Neves et al. } \\
(1998)\end{array}$ & $\begin{array}{l}\text { Valores sociais relacionados ao desemprego } \\
\text { (atribuição de causalidade) }\end{array}$ & $\begin{array}{l}\text { Relato de pesquisa } \\
\text { (descritivo) }\end{array}$ & Categoria profissional \\
\hline $\begin{array}{l}\text { Pereira e Brito } \\
(2005)\end{array}$ & $\begin{array}{l}\text { Valores sociais relacionados ao desemprego } \\
\text { (interpretações acerca do desemprego) }\end{array}$ & $\begin{array}{l}\text { Relato de pesquisa (ex- } \\
\text { ploratório) }\end{array}$ & Categoria profissional \\
\hline $\begin{array}{l}\text { Peres, Silva e } \\
\text { Carvalho (2003) }\end{array}$ & $\begin{array}{l}\text { Contexto social do desempregado (mercado } \\
\text { de trabalho) }\end{array}$ & $\begin{array}{l}\text { Relato de pesquisa } \\
\text { (descritivo) }\end{array}$ & 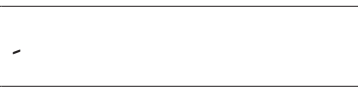 \\
\hline Pinheiro (2008) & $\begin{array}{l}\text { Saúde mental (sofrimento psíquico e/ou as- } \\
\text { pectos subjetivos) }\end{array}$ & $\begin{array}{l}\text { Relato de pesquisa (ex- } \\
\text { ploratório) }\end{array}$ & Escolaridade \\
\hline $\begin{array}{l}\text { Pinheiro e Mon- } \\
\text { teiro }(2007)\end{array}$ & $\begin{array}{l}\text { Saúde mental (sofrimento psíquico e/ou as- } \\
\text { pectos subjetivos) }\end{array}$ & $\begin{array}{l}\text { Ensaio teórico (articu- } \\
\text { lação e problematização } \\
\text { de construtos teóricos) }\end{array}$ & - \\
\hline $\begin{array}{l}\text { Polakiewicz } \\
(2006)\end{array}$ & $\begin{array}{l}\text { Saúde mental (sofrimento psíquico e/ou as- } \\
\text { pectos subjetivos) }\end{array}$ & $\begin{array}{l}\text { Relato de pesquisa (ex- } \\
\text { ploratório) }\end{array}$ & $\begin{array}{l}\text { Vinculada a programas de } \\
\text { apoio ao desempregado }\end{array}$ \\
\hline Prette (1990) & $\begin{array}{l}\text { Enfrentamento do desemprego (movimento } \\
\text { social) }\end{array}$ & $\begin{array}{l}\text { Relato de pesquisa } \\
\text { (descritivo) }\end{array}$ & Desempregados em geral \\
\hline Prette (1993) & Atuação do psicólogo (profissional) & $\begin{array}{l}\text { Ensaio teórico (reco- } \\
\text { mendação à Psicologia, } \\
\text { como ciência e profis- } \\
\text { são) }\end{array}$ & 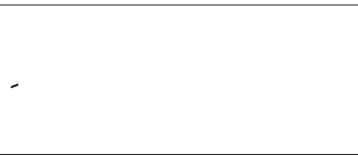 \\
\hline Ribeiro (2007) & $\begin{array}{l}\text { Saúde mental (sofrimento psíquico e/ou as- } \\
\text { pectos subjetivos) }\end{array}$ & $\begin{array}{l}\text { Ensaio teórico (reco- } \\
\text { mendação à Psicologia, } \\
\text { como ciência e profis- } \\
\text { são) }\end{array}$ & 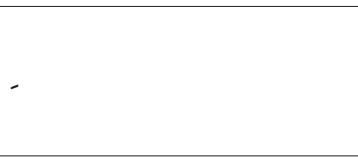 \\
\hline Ribeiro (2010) & $\begin{array}{l}\text { Saúde mental, atuação do psicólogo (profis- } \\
\text { sional) }\end{array}$ & $\begin{array}{l}\text { Ensaio teórico (reco- } \\
\text { mendação à Psicologia, } \\
\text { como ciência e profis- } \\
\text { são) }\end{array}$ & 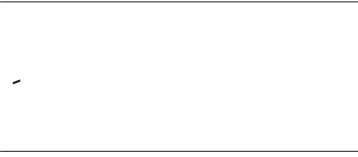 \\
\hline Rosa (1998) & $\begin{array}{l}\text { Atributos pessoais dos desempregados (to- } \\
\text { lerância à frustação) }\end{array}$ & $\begin{array}{l}\text { Relato de pesquisa } \\
\text { (descritivo) }\end{array}$ & Categoria profissional \\
\hline Rosa (1999) & $\begin{array}{l}\text { Atributos pessoais dos desempregados (to- } \\
\text { lerância à frustação) }\end{array}$ & $\begin{array}{l}\text { Relato de pesquisa } \\
\text { (descritivo) }\end{array}$ & Categoria profissional \\
\hline $\begin{array}{l}\text { Sarrieira, Câ- } \\
\text { mara e Berlim } \\
(2000)\end{array}$ & $\begin{array}{l}\text { Enfrentamento do desemprego (busca de tra- } \\
\text { balho e sobrevivência) }\end{array}$ & $\begin{array}{l}\text { Relato de pesquisa (ex- } \\
\text { ploratório) }\end{array}$ & Idade \\
\hline $\begin{array}{l}\text { Sato e Schmidt } \\
(2004)\end{array}$ & Atuação do psicólogo (profissional) & $\begin{array}{l}\text { Ensaio teórico (reco- } \\
\text { mendação à Psicologia, } \\
\text { como ciência e profis- } \\
\text { são) }\end{array}$ & 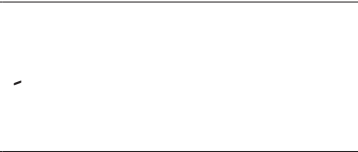 \\
\hline Schmidt (2004) & $\begin{array}{l}\text { Saúde mental (sofrimento psíquico e/ou as- } \\
\text { pectos subjetivos) }\end{array}$ & $\begin{array}{l}\text { Ensaio teórico (reco- } \\
\text { mendação à Psicologia, } \\
\text { como ciência e profis- } \\
\text { são) }\end{array}$ & 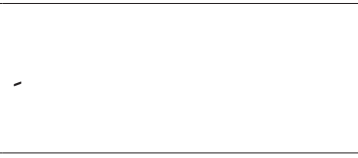 \\
\hline Souza (2008) & Contexto social do desempregado (gênero) & $\begin{array}{l}\text { Relato de pesquisa } \\
\text { (comparativo) }\end{array}$ & Gênero \\
\hline
\end{tabular}




\begin{tabular}{|c|c|c|c|}
\hline $\begin{array}{l}\text { Tagliamento } \\
(2010)\end{array}$ & Contexto social do desempregado (gênero) & $\begin{array}{l}\text { Relato de pesquisa } \\
\text { (descritivo) }\end{array}$ & Gênero \\
\hline $\begin{array}{l}\text { Terra, Carvalho, } \\
\text { Azevedo, Ve- } \\
\text { nezian e Macha- } \\
\text { do (2006) }\end{array}$ & $\begin{array}{l}\text { Saúde mental (sofrimento psíquico e/ou as- } \\
\text { pectos subjetivos) }\end{array}$ & $\begin{array}{l}\text { Relato de pesquisa } \\
\text { (comparativo) }\end{array}$ & $\begin{array}{l}\text { Vinculada a programas de } \\
\text { apoio ao desempregado }\end{array}$ \\
\hline $\begin{array}{l}\text { Urso Júnior } \\
(2005)\end{array}$ & $\begin{array}{l}\text { Saúde mental (estresse), saúde mental (sofri- } \\
\text { mento psíquico e/ou aspectos subjetivos) }\end{array}$ & $\begin{array}{l}\text { Relato de pesquisa } \\
\text { (comparativo) }\end{array}$ & $\begin{array}{l}\text { Vinculada a programas de } \\
\text { apoio ao desempregado }\end{array}$ \\
\hline Verardo (1999) & Enfrentamento do desemprego (autogestão) & $\begin{array}{l}\text { Ensaio teórico (articu- } \\
\text { lação e problematização } \\
\text { de construtos teóricos) }\end{array}$ & 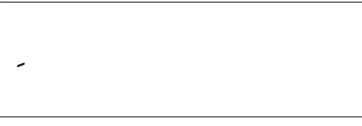 \\
\hline Vieira (2002) & $\begin{array}{l}\text { Valores sociais relacionados ao desemprego } \\
\text { (atribuição de causalidade), valores sociais } \\
\text { relacionados ao desemprego (sistema de valo- } \\
\text { res sociais) }\end{array}$ & $\begin{array}{l}\text { Relato de pesquisa } \\
\text { (comparativo) }\end{array}$ & $\begin{array}{l}\text { Vinculada a programas de } \\
\text { apoio ao desempregado }\end{array}$ \\
\hline Wilmer (2002) & $\begin{array}{l}\text { Valores sociais relacionados ao desemprego } \\
\text { (aspectos morais) }\end{array}$ & $\begin{array}{l}\text { Relato de pesquisa (ex- } \\
\text { ploratório) }\end{array}$ & Idade \\
\hline
\end{tabular}

Fonte: Pesquisa direta.

\section{Resultados e discussões}

\section{Dimensão cientométrica}

Os 58 documentos encontrados estão distribuídos em 31 artigos, 22 dissertações e cinco teses e foram produzidos por 122 autores diferentes, entre 46 primeiros-autores e 76 coautores ou orientadores. Desses 122 autores, somente 15 apresentaram mais de uma produção no tema: um com sete orientações; outro com três documentos; e 13 apresentaram duas publicações. Nesses termos, não é possível identificar nenhum pesquisador que tenha trajetória consolidada de produção no tema no Brasil, ainda mais se observados os seus interesses de pesquisa: oito deles não possuíam nenhuma linha ou projeto de pesquisa relacionado ao desemprego na época das publicações cadastrados nos seus Currículos Lattes². Assim, em muitos casos, o tema do desemprego não figura como central na trajetória acadêmica desses pesquisadores, sendo uma produção ocasional. Um dos elementos que auxiliam a entender essa configuração é o potencial de o desemprego se constituir em um construto de pesquisa autônomo, quando o Sistema Nacional de

2 Tal currículo é vinculado à Plataforma Lattes (http://lattes.cnpq. br), a qual é coordenada pelo Conselho Nacional de Desenvolvimento Científico e Tecnológico (CNPq) e tem o objetivo de integrar e divulgar o histórico acadêmico e profissional de estudantes e pesquisadores que atuam, principalmente, no Brasil.
Pós-Graduação brasileiro prevê linhas de pesquisas amplas, que congreguem diversos interesses (Menandro, 2003). Em relação à distribuição geográfica, o Sudeste e o Sul são as regiões do Brasil que mais produzem sobre o desemprego, conforme apresentado na Tabela 3.

A concentração nas duas primeiras regiões é influenciada pela alta produção circunscrita a São Paulo (50\%; 29 trabalhos) e Rio Grande do Sul (20.7\%; 12 trabalhos), estados que sediam duas instituições de destaque na produção sobre o tema em questão: a Universidade de São Paulo (USP) (32.7\%; 19 trabalhos) e a Universidade do Vale do Rio dos Sinos (Unisinos) (13.7\%; oito trabalhos), respectivamente. Soma-se a esses dados o fato de estarem localizados na USP o periódico científico que mais publicou artigos sobre esse tema — os Cadernos de Psicologia Social do Trabalho (29\%; nove artigos) - e o programa de pós-graduação com maior número de dissertações $(18.2 \%$; quatro — semelhante à Unisinos) e teses (40\%; duas) defendidas.

Os outros periódicos que publicaram sobre o tema foram Revista Psicologia: Organizações e Trabalho (12.9\%; quatro), Psicologia \& Sociedade (9.7\%; três), Aletheia (6.5\%; dois) e Psicologia: Teoria e Prática (6.5\%; dois). Ainda existem outros 11 periódicos nessa listagem, cada um com uma publicação sobre o tema.

Esses índices de concentração da produção podem indicar a existência de dois polos de produção 
TABELA 3

Década de publicação e região geográfica do vínculo institucional do primeiro autor dos documentos analisados

\begin{tabular}{lll}
\hline & N & $\%$ \\
\hline Região & 34 & 58.6 \\
Sudeste & 15 & 25.9 \\
Sul & 04 & 06.9 \\
Nordeste & 03 & 05.2 \\
Centro-Oeste & - & - \\
Norte & & \\
Década de publicação & 01 & 01.7 \\
1980 & 07 & 12.1 \\
1990 & 43 & 74.1 \\
2000 & 07 & 12.1 \\
2010 & & \\
\hline
\end{tabular}

Fonte: Pesquisa direta.

de conhecimento em Psicologia sobre o desemprego: a USP e a Unisinos. Isso pode ser explicado pelo fato de o eixo Sudeste-Sul do Brasil ser apontado como o maior produtor de conhecimento em todas as áreas, estimulado tanto pelos altos investimentos estatais nas instituições localizados nessa região como pela antiguidade de suas estruturas de pesquisas (Cavalcante, 2011). Ademais, foi nos estados onde estão localizadas essas instituições que ocorreram os maiores embates entre os trabalhadores e o capital — materializados nas grandes greves de 1970 fenômeno que pode ter impulsionado a Psicologia a visualizar e aderir diretamente às demandas apresentadas pela classe trabalhadora, como a própria questão do desemprego.

Quanto ao período em que esse material foi produzido, os primeiros trabalhos foram publicados na segunda metade da década de 1980, mas somente na década de 2000 é que essa produção acelerou. Comparando com a produção dos países centrais, nota-se um distanciamento temporal: enquanto na década de 1930 alguns estudos de grande porte já eram gestados nesses países, apenas no final da década de 1980 é que a comunidade científica no Brasil passou por essa experiência.

Esse distanciamento pode ser compreendido considerando-se, principalmente, dois elementos: o histórico de estruturação da Psicologia nesses lugares e o cenário socioeconômico brasileiro. Em relação ao primeiro elemento, enquanto no começo do século XX os Estados Unidos e diversos países da Europa Ocidental já tinham estruturado o campo científico e profissional da Psicologia, o Brasil ainda dava os primeiros passos nessa direção (Gomes, 2003). Quanto ao segundo elemento, destaca-se que foi apenas no final da década de 1980 que o desemprego começou a ganhar maiores proporções no Brasil, alcançando os seus piores índices na década de 1990, durante os dois governos de Fernando Henrique Cardoso. Já em meados da década de 2000, as taxas de desemprego paulatinamente caíram, retornando a índices semelhantes aos da década de 1980 (Pochmann, 2006).

A análise desses dados sugere haver alinhamento entre a dinâmica do desemprego no país e a produção em Psicologia sobre esse tema, uma vez que, nas mesmas décadas em que esse fenômeno se apresentou com maior força em solo nacional, a Psicologia passou a atentar mais para seus efeitos. Desse modo, o relativo acompanhamento da Psicologia ao agravamento do desemprego em solo nacional pode ser um indicador positivo da atenção dessa área do conhecimento às demandas que são originárias da classe trabalhadora. 
TABELA 4

Tipo e delineamento dos estudos

\begin{tabular}{lllc}
\hline \multicolumn{1}{c}{ Tipos de estudos } & \multicolumn{1}{c}{ Delineamentos } & N & $\%$ \\
\hline Pesquisas empíricas & & 43 & 74.1 \\
& Estudos comparativos & 15 & 31.3 \\
& Estudos exploratórios & 12 & 25.0 \\
& Estudos descritivos & 12 & 25.0 \\
& Estudos explicativos & 08 & 18.8 \\
\hline Ensaios teóricos & Articulação e problematização de construtos & 06 & 17.2 \\
& teóricos & 10 & 60.0 \\
& Recomendação à Psicologia, como ciência e & 04 & 40.0 \\
\hline profissão & 05 & 8.6 \\
\hline
\end{tabular}

Fonte: Pesquisa direta.

\section{Dimensão metodológica}

A Tabela 4 condensa os números acerca dos tipos de pesquisa, bem como os seus respectivos delineamentos. De acordo com ela, prevalecem as pesquisas empíricas, seguidas dos ensaios teóricos e dos relatos de experiência. Notadamente, a presença das dissertações e das teses inflacionou a quantidade de trabalhos empíricos, já que esse é o formato de pesquisa privilegiado nessas publicações. Quanto aos ensaios teóricos, eles dedicam-se a estabelecer articulações, problematizar construtos teóricos ou estabelecer recomendações para a Psicologia, seja na produção de conhecimento, seja na intervenção profissional. Já os relatos de experiência são produzidos com base, majoritariamente, em projetos de extensão conduzidos em meio acadêmico.

Detendo-se nos delineamentos das pesquisas empíricas, observa-se que a produção sobre o tema desemprego, na Psicologia brasileira, tende, primeiramente, a realizar comparações entre aspectos desse fenômeno; em segundo lugar, a identificar, descrever ou aprofundar variáveis associadas a ele; e por fim, a tentar estabelecer relações de causa e efeito. Cronologicamente, percebe-se que as décadas de 1980 e 1990 foram marcadas exclusivamente por estudos de cunho exploratório (um trabalho) e descritivo (cinco trabalhos); nos dois períodos posteriores - 2000 e 2010 -, estudos desse calibre continuaram a ser produzidos (dez pesquisas exploratórias e seis descritivas), contudo, paralelamente surgiram, em maior volume, os trabalhos comparativos e explicativos (respectivamente, dentro do mesmo período, 15 e oito publicações).

Para um campo que apresenta determinadas dificuldades de estruturação - pela reduzida quantidade tanto de materiais publicados como de autores que se dediquem à produção no tema -, chama a atenção ser encontrado volume proporcionalmente considerável de estudos que extrapolam os níveis descritivos ou exploratórios, propondo arranjos comparativos e explicativos, ainda mais quando se considera que o adensamento da produção nas duas últimas décadas foi fomentado por esses dois últimos tipos de estudos.

Quanto ao corte populacional adotado, de acordo com os valores apresentados na Tabela 5, há prevalência pela escolha de sujeitos que procuram algum serviço de apoio ao trabalhador desempregado - como o Sistema Nacional de Emprego (Sine). Ademais, grupos específicos da população desempregada ou são pouco estudadas (no caso, os recortes por gênero, idade e escolaridade), ou nem são contempladas nos trabalhos analisados (como recortes de raça/etnia, deficiência física ou extrato socioeconômico). 
TABELA 5

Parcela da população estudada nas pesquisas empíricas da Psicologia brasileira sobre o desemprego

\begin{tabular}{lcc}
\hline \multicolumn{1}{c}{ Parcela da população estudada } & N & $\%$ \\
\hline Vinculada a programas de apoio ao desempregado & 14 & 35 \\
Categoria profissional & 9 & 22.5 \\
Desempregados em geral & 9 & 22.5 \\
Gênero & 2 & 5 \\
Faixa etária & 2 & 5 \\
Escolaridade & 2 & 5 \\
Psicólogos que trabalham com desempregados & 2 & 5 \\
\hline
\end{tabular}

Fonte: Pesquisa direta.

\section{Dimensão temática}

Com relação aos aspectos do desemprego analisados pelos autores em suas pesquisas a Tabela 6 traz informações importantes.

Prioritariamente, os estudos direcionam-se para o tema da saúde mental. Dentro desse tópico, a maior parte dos trabalhos investiga o sofrimento psíquico e os efeitos subjetivos que a situação de desemprego inflige aos trabalhadores, sendo seguida por pesquisas sobre: ansiedade, bem-estar psicológico, estresse, medo, qualidade de vida e uso de drogas. Essas pesquisas são empíricas (20 dos 25 materiais dessa categoria), distribuídas em estudos de caráter comparativo (10 dos 25 estudos), explicativo (cinco dos 25 estudos), exploratório (quatro de 25 estudos) e descritivo (um dos 25 estudos). Portanto, os trabalhos em questão investigam relações entre variáveis, notadamente os efeitos do desemprego sobre - e as relações deste com — dimensões da saúde mental do trabalhador.

Destacam-se, também, as publicações que tratam do contexto social dos desempregados. Essas pesquisas propõem-se a atentar para elementos da dinâmica societária que se relacionam ao fenômeno do desemprego, marcadamente: o mercado de trabalho, a qualificação profissional, o suporte social e as relações de gênero. Nessa categoria, os estudos são também, preponderantemente, empíricos (11 dos 13 materiais dessa categoria), distribuídos entre os quatro tipos de delineamentos. Com isso, essas pesquisas exploram e descrevem determinados aspectos do contexto social e estabelecem relações e explicações entre esses elementos e o desemprego.

\section{TABELA 6}

Aspectos do desemprego abordados nos estudos em Psicologia

\begin{tabular}{lll}
\hline \multicolumn{1}{c}{ Aspectos estudados nos documentos da amostra } & N & $\%$ \\
\hline Saúde mental & 25 & $43.1 \%$ \\
Contexto social do desempregado & 13 & $22.4 \%$ \\
Enfrentamento do desemprego & 12 & $20.7 \%$ \\
Atuação do psicólogo & 9 & $15.5 \%$ \\
Valores sociais relacionados ao desemprego & 8 & $13.8 \%$ \\
Atributos pessoais dos desempregados & 8 & $13.8 \%$ \\
\hline
\end{tabular}

Nota. Apesar de o n de referência ser o dos documentos (58), os estudos abordavam mais de um aspecto, inviabilizando a soma dos valores dessa tabela.

Fonte: Pesquisa direta. 
Outro tópico investigado pelos escritos trata do modo como os desempregados têm enfrentado o desemprego. Os delineamentos dessas pesquisas denotam a intenção dos pesquisadores de rastrear as ações empreendidas pelos trabalhadores para amenizar ou sair da situação de desemprego, já que esse grupo é composto, basicamente, por estudos empíricos (10 de 12 trabalhos) exploratórios e descritivos (seis de 12 pesquisas). Chamam a atenção dois trabalhos que tratam dos movimentos sociais dos desempregados, bem como um sobre estratégias de empresas autogestionadas, como formas coletivas de a classe trabalhadora se organizar tendo em vista o enfrentamento dessa situação. Os demais materiais, de maneira geral, se detêm nas estratégias utilizadas pelos desempregados para buscar uma inserção no mundo do trabalho, bem como para sobreviver a essa situação.

Também há nove trabalhos que se referem à atuação do psicólogo voltada para a população desempregada. Refletindo a aparente escassez de ações diretas desse profissional sobre a questão do desemprego, os estudos que compõem essa categoria ora descrevem práticas desenvolvidas no escopo de extensões acadêmicas - três relatos de experiência e três pesquisas empíricas —, ora dedicam-se a prescrever possíveis atuações profissionais diante desse fenômeno - um ensaio teórico.

Soma-se às categorias até agora apresentadas uma referente aos valores sociais associados ao desemprego. No geral, são pesquisas empíricas dos mais diversos delineamentos e que investigam tanto os valores atribuídos aos trabalhadores desempregados pelos outros membros da sociedade — por exemplo, estigma, discriminação, aspectos morais e valores sociais - como a imagem que os desempregados constroem sobre si mesmos - por exemplo, as interpretações sobre o desemprego e as atribuições de causalidade (responsabilidade pela situação de desemprego).

Por fim, há materiais que versam a respeito de alguns aspectos pessoais dos desempregados. Essas investigações, que são, em sua maioria, empíricas (sete dos oito trabalhos), procuram descrever características específicas (dois materiais) ou comparar a relação entre a situação de desemprego e alguns atributos do trabalhador desempregado (metade dos estudos). Estão incluídos nesse conjunto trabalhos acerca das habilidades pessoais dos sujeitos, da tolerância à frustração e das habilidades sociais dos indivíduos.

De maneira geral, os temas desses trabalhos evidenciam que a aproximação, por excelência, da Psicologia com a investigação do desemprego ocorre pela atenção a aspectos referentes aos trabalhadores desempregados. Por outro lado, também se percebe que o conjunto dos documentos dedica-se igualmente a tratar tanto de tópicos tradicionais da Psicologia, aplicando-os ao fenômeno do desemprego, quanto de temáticas novas para esse campo, chegando também a coexistir, em alguns materiais, ambas as perspectivas. Quanto ao primeiro grupo de estudos, eles versam sobre a saúde mental dos trabalhadores e dos atributos pessoais destes. Essa tendência reproduz a aproximação que a Psicologia realiza com o tema em tela nos países centrais do capitalismo, como descrito por Feather (1990) e Pérez (2007), denunciando um dos efeitos deletérios dessa situação para os trabalhadores.

Já o segundo conjunto de temas se preocupa com aspectos da dinâmica social inerente à situação de desemprego e ao modo como os trabalhadores enfrentam essa situação. Assim, uma parcela dos estudos dedica-se a escrutinar as formas com que os trabalhadores enfrentam o desemprego e sobrevivem a ele e os valores e outros elementos sociais (mercado de trabalho, suporte social, dentre outros) que perpassam essa vivência. Possivelmente, esses estudos ecoam, direta ou indiretamente, alguns postulados gestados na Psicologia brasileira — e latino-americana — por volta da década de 1970. Sabe-se que, nesse período, ganhou corpo um movimento, iniciado na Psicologia Social, que colocava em pauta a necessidade de essa ciência atentar para os elementos contextuais, sociais e concretos da vida dos sujeitos, a fim de desconstruir uma concepção abstrata dos indivíduos e aproximar a Psicologia dos anseios das classes menos abastadas da sociedade (González Rey, 2004; Lane, 1989; Martín-Baró, 1985).

Analisando cronologicamente o desenvolvimento desses programas de pesquisa - um voltado para a saúde mental e para os aspectos individuais 
do desempregado, e outro dedicado aos elementos sociais e ao enfrentamento do desemprego —, percebe-se que ambos tiveram uma tendência semelhante de crescimento ao longo das décadas, conforme apresentado pela Figura 1. Com isso, ao menos em termos quantitativos, é possível afirmar que ambos os programas tiveram igual importância para a estruturação atual do campo de pesquisa da Psicologia sobre o desemprego.

Por fim, foram analisadas as contribuições dessas pesquisas, o que esteve explícito em 30 trabalhos e foi exposto na Tabela 7.
Diante desse quadro, é possível perceber que a comunidade científica brasileira de Psicologia apresenta uma preocupação em fomentar alternativas práticas de lidar com o desemprego, que podem ser realizadas por profissionais, políticas, serviços ou pela própria Psicologia, ficando em segundo plano preocupações com formulações teóricas mais amplas. Ainda, resgatando a década de publicação de cada documento, nota-se que, paulatinamente, os autores foram expandindo o espectro do tipo de contribuição que oferecem ao campo de pesquisa sobre o desemprego: enquanto na década de 1990

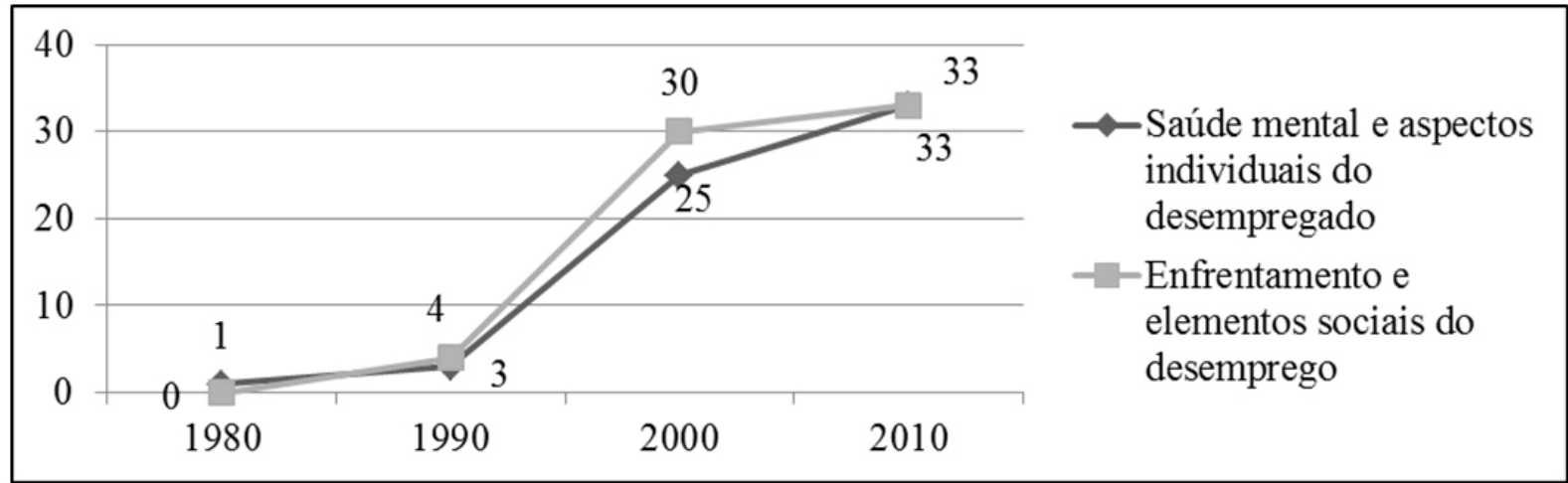

Figura 1. Distribuição temporal dos documentos conforme o aspecto do desemprego.

Fonte: pesquisa direta.

TABELA 7

Tipo e âmbito da contribuição dos estudos

Tipo e âmbito de contribuição

$\mathrm{N}$

Tipo de contribuição

Intervenções práticas sobre o desemprego

Avanços teóricos

Intervenções práticas e avanços teóricos

Âmbito da contribuiçãoa

Atributos pessoais dos desempregados

Debates da Psicologia

Compreensão do fenômeno desemprego

Melhoria dos serviços de atendimento ao desempregado

Estruturação de políticas públicas de combate ao desemprego

Melhoria das condições de vida dos desempregados

a. Em alguns casos, os materiais apresentavam contribuições em mais de um aspecto; desse modo, o n adotado para a formulação da porcentagem é 39 .

Fonte: pesquisa direta.
$12 \quad 40.0$

$4 \quad 13.0$

$11 \quad 28.2$

9

8

8

$3 \quad 7.7$


apenas eram encontrados trabalhos que contribuíam para os avanços dos debates da Psicologia, para a estruturação das políticas públicas e para a compreensão teórica do desemprego, na década seguinte se tornou presente a preocupação com a melhoria dos serviços e das condições de vida dos trabalhadores desempregados.

\section{Considerações finais}

O estudo acerca do desemprego representa um desafio tanto do ponto de vista da produção científica como do posicionamento político. No primeiro caso, o fenômeno em tela pressiona a Psicologia a rever suas bases teóricas e metodológicas, levando-a a se aproximar de pressupostos que integrem os elementos históricos, sociais e culturais no modo de compreender e investigar a experiência humana. Isso ocorre na medida em que a vivência do desemprego por parte dos trabalhadores concatena, inalienavelmente, dimensões objetivas e subjetivas. No campo político, por sua vez, a existência de índices de desemprego ainda alarmantes força a tomada de posição de acadêmicos e profissionais quanto àquilo a que serve o conhecimento produzido (e a quem ele serve): para responsabilizar o desempregado pela sua situação, restringindo a análise sobre o fenômeno ao plano individual, ou para apontar os impactos e os determinantes do desemprego, localizando-os na conformação societária que o engendra?

Essa pergunta abre espaço para se pensar em quais poderiam ser as vias de acesso da Psicologia Social Crítica para o tema do desemprego. De fato, o que parece caracterizá-la é a possibilidade de vincular os problemas vividos pelos trabalhadores desempregados com o sistema social no qual o desemprego é gerado. Essa afirmação precisa ser colocada contra um fundo histórico.

Historicamente, a Psicologia entrou nos contextos de trabalho com o intuito de otimizar o desempenho humano e de evitar os problemas causados pelo taylorismo e pela exploração da força de trabalho (como desmotivação, fadiga, adoecimento). Grande parte dos recursos, teóricos e metodológicos, da Psicologia Organizacional e do Trabalho foi, portanto, desenvolvida para a atuação com traba- lhadores ativos, negligenciando o desemprego como uma questão estrutural e inerente ao capitalismo.

Contudo, pelas razões expostas neste artigo, a situação começa a mudar, primeiro, devido ao crescimento cíclico do desemprego; segundo, e mais importante, porque se começa a perceber que o desemprego traz consequências psicossociais nefastas, inclusive com reflexos indiretos sobre os que estão empregados. Então, a Psicologia passa a estudar o desemprego, porém numa perspectiva simplista de extensão dos referenciais teóricos de um contexto de emprego a um de desemprego: daí a ênfase nos estudos sobre os impactos do desemprego na saúde mental, numa clara psicologização de um fenômeno, em si, social. Mais recentemente, há uma tendência a se enfatizar os mecanismos de enfrentamento (coping), mas ainda com base na visão de um sujeito psicológico que precisa ser "empoderado" para lidar, individualmente, com a situação.

Nesse contexto, a Psicologia Social do Trabalho (Crítica) tem diante de si ao menos três vias de acesso ao tema do desemprego. Uma delas é pela crítica à transformação do desemprego em uma questão estritamente psicológica e pela integração de outros elementos oriundos do contexto histórico social para a sua compreensão. Com essa tarefa, a Psicologia avança no sentido de denunciar a individualização da classe que vive do trabalho. Como consequência, uma segunda via é a diversificação temática para além da relação "desemprego e saúde mental". Com isso, não se desmerece essa tradição de pesquisa, mas se ressalta a possibilidade de que os demais tópicos (contexto social do desempregado e atuação do psicólogo, por exemplo) tragam contribuições inovadoras para esse campo, problematizando o modo como, costumeiramente, a Psicologia vem conduzindo as suas pesquisas e selecionando os seus interesses no que se refere ao desemprego. Nessa direção, a atenção a outras parcelas da classe trabalhadora (mulheres, negros, deficientes, jovens, pessoas com escolaridade baixa), bem como a população que escape do eixo Sul-Sudeste, pode ser caminho alternativo para essa expansão.

Uma terceira via de entrada da Psicologia Social Crítica no contexto do desemprego é por meio de um questionamento radical: se a construção da 
subjetividade do trabalhador no capitalismo esteve associada à realização de um trabalho, como esse processo ocorre entre aqueles que por alguma razão não estão vendendo a sua força de trabalho? $\mathrm{O}$ método adotado neste artigo, baseado em análise de documentos, não permite uma resposta a essas questões, porém sinaliza lacunas importantes da literatura da Psicologia, pois, até o momento, parece não haver uma reflexão profunda sobre os processos paradoxais de constituição da subjetividade dos trabalhadores submetidos a essa situação. Isso leva ao último comentário deste artigo.

Quais as implicações dos achados deste artigo para outros pesquisadores em Psicologia na América Latina? O caso brasileiro revela, para si e para os demais da América Latina, a necessidade de se multiplicar os estudos que evidenciem os efeitos deletérios do desemprego, não só para a saúde mental dos trabalhadores, mas também para a construção da resistência dessa classe diante das investidas do capital. Da mesma forma, é relevante o acento em trabalhos que colaborem para os processos de luta desses sujeitos em face da situação de desemprego e a elaboração e a divulgação de intervenções dos psicólogos nessa direção.

Assim, a apresentação desse levantamento pretende instalar um debate na comunidade científica de Psicologia na América Latina quanto às possibilidades de esse campo fomentar saberes e fazeres que corroborem a supressão das relações de exploração entre os seres humanos. A identificação dos rumos tomados pela produção brasileira, de algum modo, reflete a forma como esse tema vem sendo tratado pela Psicologia e, ao mesmo tempo, interroga se essas outras comunidades científicas apresentam caminhos diversos - e mais efetivos - de aproximação da Psicologia com a compreensão do desemprego e o combate a ele.

\section{Referências}

Ackermann, K., Amaral, M. A., Silva, J. C. B., Geraldes, A. L., Lima, T. N., Lombardi Júnior, M., et al. (2005). O desemprego do tempo: narrativas de trabalhadores desempregados em diferentes ambientes sociais. Cadernos de Psicologia Social do Trabalho, 8, 1-27.
Ackermann, K. (2007). Mercado de trabalho invisivel: a articulação entre o trabalho no mercado informal, o emprego e o desemprego na trajetória de trabalhadores. Dissertação de Mestrado não publicada, Universidade de São Paulo, São Paulo, Brasil.

Álvaro, J. L. (1992). Desempleo y bienestar psicológico. Madrid: Siglo XXI.

Araújo, J. N. G., Monteiro, L. S. S., Lima, S. T. N., \& Souza, D. F. X. (2006). Trabalhadores em situação de desemprego: uma experiência de apoio psicológico. Mental, 4(7), 107-125.

Argolo, J. C. T. (2001). O impacto do desemprego sobre o bem- estar psicológico dos trabalhadores da cidade de Natal. Dissertação de Mestrado não publicada, Universidade Federal do Rio Grande do Norte, Natal, Brasil.

Argolo, J. C. T., \& Araújo, M. A. D. (2004). O impacto do desemprego sobre o bem-estar psicológico dos trabalhadores da cidade de Natal. Revista de Administração Contemporânea, 8(4), 161-182.

Azevedo, J. T., Bogre, M. C., Bombardi, V. M., Chen, M. C., Mapo, E. Y., Martins, A. N., et al. (1998). As estratégias de sobrevivência e de busca de emprego adotadas pelos desempregados. Cadernos de Psicologia Social do Trabalho, 1(1), 15-42.

Baccaro, A. (1987). Atitude do indivíduo desempregado (uma análise sócio-psicológica). Dissertação de Mestrado não publicada, Pontifícia Universidade Católica de São Paulo, São Paulo, Brasil.

Barros, C. A., \& Oliveira, T. L. (2009). Saúde mental de trabalhadores desempregados. Revista Psicologia: Organizações e Trabalho, 9(1), 86-107.

Batista, N. C. S. (2005). Pegado fila: contando um pouco da cotidianidade do trabalhador desempregado na cidade de São Paulo. Dissertação de Mestrado não publicada, Pontifícia Universidade Católica de São Paulo, São Paulo, Brasil.

Beales, H. L., \& Lambert, R. S. (1934). Memoirs of the unemployed. London: Gollanz.

Bendassolli, P. F. (2009). Psicologia e trabalho: apropriações e significados. São Paulo: Cengage Learning.

Bezerra-Ribeiro, M. (2008). Percepção de suporte social e consumo de álcool em desempregados. Dissertação de Mestrado não publicada, Universidade Metodista de São Paulo, São Paulo, Brasil.

Borcsik, S. P. L. (2006). Avaliação da ansiedade e do enfrentamento de executivos em situação de desemprego. 
Dissertação de Mestrado, Universidade Metodista de São Paulo, São Bernardo do Campo, Brasil.

Borges-Andrade, J. E., \& Pagotto, C. P. (2010). O estado da arte da pesquisa brasileira em psicologia do trabalho e organizacional [Número Especial]. Psicologia: Teoria e Pesquisa, 26, 37-50.

Bottcher, A. G. M. (2012) Processo de recolocação profissional de executivos: Interação entre stress e habilidades sociais. Dissertação de Mestrado não publicada, Programa de Pós-Graduação em Psicologia da Pontifícia Universidade Católica de Campinas, Campinas, SP, Brasil.

Brandão, M. G. A. (2003). Impactos da perda do emprego e o papel da qualificação no processo de reinserção no mercado de trabalho. Tese de Doutorado não publicada, Programa de Pós-Graduação em Educação da Universidade Federal da Bahia, Salvador, Brasil.

Caldana, A. C. F. (2000). Desemprego e qualidade de vida: estratégias de inclusão social e sobrevivência. Dissertação de Mestrado não publicada, Universidade de São Paulo, Ribeirão Preto, Brasil.

Campos, D. C. (2011). Autoeficácia e saúde mental em trabalhadores desempregados. Dissertação de Mestrado não publicada, Pontifícia Universidade Católica de Goiás, Goiânia, Brasil.

Campos, K. C. L., Duarte, C., Cezar, E. O., \& Pereira, G. O. A. (2011). Psicologia organizacional e do trabalho: retrato da produção científica na última década. Psicologia: Ciência e Profissão, 31(4), 702-717.

Cardoso, G. R. (2004). "Estou desempregado, não desesperado": a vivência do desemprego para trabalhadores desempregados frequentadores do SINE da cidade de Florianópolis. Dissertação de Mestrado não publicada, Universidade Federal de Santa Catarina, Florianópolis, Brasil.

Carlotto, M. S., \& Gobbi, M. D. (2001). Desempleo y sindrome de burnout. Revista de Psicologia, 10(1), 131-139.

Carlotto, M. S., Gobbi, M. D., \& Reichert, C. B. (2001). Desenvolvimento da empregabilidade: uma intervenção psicossocial. Aletheia, 13, 111-118.

Cascio, W. F., \& Aguinis, H. (2008). Research in industrial and organizational Psychology from 1963 to 2007: Changes, choices, and trends. Journal of Applied Psychology, 93(5), 1062-1081.
Castelhano, L. M. (2005). O medo do desemprego e a(s) nova(s) organizações de trabalho. Psicologia ES Sociedade, 17(1), 17-28.

Castelhano, L. M. (2006). A perda do emprego, suas implicações subjetivas e as consequências para o laço social: uma contribuição psicanalítica. Dissertação de Mestrado não publicada, Pontifícia Universidade Católica de São Paulo, São Paulo, Brasil.

Cavalcante, L. R. (2011). Desigualdades regionais em ciência, tecnologia e inovação (CTEI) no Brasil: uma análise de sua evolução recente. Rio de Janeiro: IPEA.

Coêlho, M. R. A. (2007). Atribuição de causalidade e desemprego. Tese de Doutorado não publicada, Universidade do Estado do Rio de Janeiro, Rio de Janeiro, Brasil.

Costa, M. S. (2005). Qualificação profissional e ideologia: estudo com trabalhadores desempregados em busca de emprego. Dissertação de Mestrado não publicada, Universidade de São Paulo, São Paulo, Brasil.

Cruz, D. V. A. (2008). Práticas clínicas da psicologia frente ao sofrimento psíquico causado pelo desemprego contemporâneo. Dissertação de Mestrado não publicada, Universidade Vale do Rio dos Sinos, São Leopoldo, Brasil.

Diogo, M. F., \& Coutinho, M. C. (2006). A dialética da inclusão/exclusão e o trabalho feminino. Interações, 11(21), 121-142.

Farina, A. S., \& Neves, T. F. S. (2007). Formas de lidar com o desemprego: possibilidades e limites de um projeto de atuação em psicologia social do trabalho. Cadernos de Psicologia Social do Trabalho, 10(1), 21-36.

Feather, N. (1990). The psycological impact of unemployment. New York: Springe-Verlag.

Felisberto, R. F. T. (2001). Tenho um diploma universitário, mas não tenho emprego: histórias de vida de pessoas que vivem a experiência do desemprego. Dissertação de Mestrado não publicada, Universidade Federal de Santa Catarina, Florianópolis, Brasil.

Freitas, R. (2000). O trabalhador desempregado diante do caos e do sofrimento psíquico: $O$ despertar do avesso. Dissertação de Mestrado não publicada, Universidade Paulista Júlio de Mesquita Filho, Franca, Brasil.

Garrido, P. B., Paiva, V., Nascimento, V. L. V., Sousa, J. B., \& Santos, N. J. S. (2007). Aids, estigma e de- 
semprego: implicações para os serviços de saúde. Revista de Saúde Pública, 41(2), 72-79.

Gomes, W. B. (2003). Pesquisa e prática em psicologia no Brasil. In O. H. Yamamoto \& V. V. Gouveia (Orgs.), Construindo a psicologia brasileira: desafios da ciência e prática psicológica (pp. 23-59). São Paulo: Casa do Psicólogo.

Gómez, R. P., Morejó, A. R., \& Sabater, C. R. (2008). Expectativas y duración del desempleo. Revista de Psicologia del Trabajo y las Organizaciones, 24(2), 129-151.

Gondim, S. M. G., Almeida, A. B., Pena, A. C., \& Filgueiras, J. (2001). Aconselhamento profissional a desempregados: Relato de uma experiência de formação acadêmica para o psicólogo organizacional e do trabalho. Revista Psicologia: Organizações e Trabalho, 1(2), 45-72.

González Rey, F. L. (2004). La crítica en la psicología social latinoamericana y su impacto en los diferentes campos de la psicología. Interamerican Journal of Psychology, 38(2), 351-360.

Goulart, P. M. (2003). Sem medo do desemprego: o caso do movimento dos trabalhadores desempregados. Psicologia E Sociedade, 15(1), 137-160.

Guilland, R. (2010). Jovem em situação de desemprego: habilidades sociais e bem-estar psicológico. Dissertação de Mestrado não publicada, Universidade do Vale do Rio dos Sinos, São Leopoldo, Brasil.

Guilland, R., \& Monteiro, J. K. (2010a). Jovens e desemprego: estado da arte. Revista Psicologia: Organizações e Trabalho, 10(2), 145-158.

Guilland, R., \& Monteiro, J. K. (2010b). Jovem em situação de desemprego: habilidades sociais e bem-estar psicológico. Psicologia: Teoria e Prática, 12(3), 149-163.

Harvey, D. (2010). Condição pós-moderna: uma pesquisa sobre a origem das mudanças culturais. São Paulo: Loyola.

Iribarría, J. A. O., Ruiz, M. A., Pardo, A., \& Martín, R. S. (2002). Efectos de la duración del desempleo entre los desempleados. Psicothema, 14(2), 440-443.

Jahoda, M. (1979). The impact of unemployment in the 1930s and 1970s. Bulletin of the British Psychological Society, 32, 309-314.

Jahoda, M. (1982). Employment and unemployment: a social-psychological analysis. Cambridge: Cambridge University Press.
Lane, S. T. M. (1989). A psicologia social e uma nova concepção do homem para a psicologia. In S. T. M. Lane \& W. Codo (Orgs.), Psicologia social: o homem em movimento (pp. 10-19). São Paulo: Brasiliense.

Leal, M. S., Aguillera, F., \& Melo-Silva, L. L. (2011). Revista psicologia: organizações e trabalho: uma década de sua produção científica em análise. Revista Psicologia: Organizações e Sociedade, 11(2), 6-20.

Mandelbaum, B. (2004). O desemprego em situação: esboços de estruturação de uma clínica social. Tese de Doutorado não publicada, Universidade de São Paulo, São Paulo, Brasil.

Martín-Baró, I. (1985). El papel del psicólogo en el contexto centroamericano. Boletín de Psicología, 4(17), 99-112.

Marx, K. (2010). O capital: crítica da economia política. Rio de Janeiro: Civilização Brasileira. (Originalmente publicado em 1867)

Menandro, P. R. (2003). Linha de pesquisa: possibilidades de definição e tipos de utilização do conceito. Revista de Administração Contemporânea, 7(2), 177-182.

Monteiro, J. K., Pesenti, C. M., Maus, D., Bottega, D., \& Machado, F. R. (2008). Reflexões acerca do atendimento psicológico a desempregados. Aletheia, 27(1), 233-242.

Neves, T. F. S. (2006). Ensaios sobre o desemprego: qualidades de um "novo" trabalhador? Imaginário, 12(13), 123-141.

Neves, T. F. S., Ortega, C. A., Barreto, R. A., Kim, C., Müller, E., Costa, F. B., et al. (1998). Desemprego e ideologia: As explicações das causas do desemprego utilizadas por trabalhadores metalúrgicos. Cadernos de Psicologia Social do Trabalho, 1(1), 1-13.

Organización Internacional del Trabajo. (2012). Panorama laboral 2012: América Latina y el Caribe. Lima: Autor.

Pereira, M. C., \& Brito, M. J. (2005). Reestruturação produtiva e os sentidos do desemprego: uma abordagem interpretativa de trajetórias de trabalhadores excluídos do mercado de trabalho industrial de Lavras-MG. Revista Psicologia: Organizações e Trabalho, 5(2), 65-99.

Peres, R. S., Silva, J. A., \& Carvalho, A. M. R. (2003). Um olhar psicológico acerca do desemprego e da precariedade das relações de trabalho. Psicologia: Teoria e Prática, 5(1), 97-110. 
Pérez, S. M. (2007). Diferencias individuales de los desempleados y constructos motivacionales: una relación de interdependencia predictora del desempleo estructural. Revista de Psicología del Trabajo y de las Organizaciones, 21(3), 269-297.

Pinheiro, L. R. S. (2008). A saúde mental dos trabalhadores com ensino superior em situação de desemprego. Dissertação de Mestrado não publicada, Universidade Vale do Rio dos Sinos, São Leopoldo, Brasil.

Pinheiro, L. R. S., \& Monteiro, J. K. (2007). Refletindo sobre desemprego e agravos à saúde mental. $\mathrm{Ca}$ dernos de Psicologia Social do Trabalho, 10(2), 35-45.

Polakiewicz, E. M. (2006). A crise atual do trabalho e seus reflexos na comunidade israelita de Belo Horizonte: 0 projeto AVIV. Dissertação de Mestrado não publicada, Universidade Federal de Minas Gerais, Belo Horizonte, Brasil.

Prette, A. D. (1990). Movimentos sociais em uma perspectiva psicológica social: o movimento de luta contra o desemprego. Tese de Doutorado não publicada, Universidade de São Paulo, São Paulo, Brasil.

Prette, A. D. (1993). O desemprego crônico no país: aspectos sociais e psicológicos. Estudos de Psicologia (Campinas), 10(1), 119-130.

Ribeiro, M. A. (2007). Psicose e desemprego: um paralelo entre experiências psicossociais de ruptura biográfica. Cadernos de Psicologia Social do Trabalho, 10(1), 75-91.

Ribeiro, M. A. (2010). Estratégias micropolíticas para lidar com o desemprego: contribuições da Psicologia Social do Trabalho. Psicologia Política, 9(18), 331-346.

Rosa, S. (1998). Tolerância à frustração no desemprego: um estudo com trabalhadores do ABC. Dissertação de Mestrado não publicada, Universidade Metodista de São Paulo, São Paulo, Brasil.

Rosa, S. (1999). Tolerância à frustração em trabalhadores desempregados no Grande ABC. Mudanças, 4(11), 135-187.

Santos, R. N. M., \& Kobashi, N. Y. (2009). Bibliometria, cientometria, infometria: conceitos e aplicações. Tendências da Pesquisa Brasileira em Ciência da Informação, 2(1), 155-172.

Sarriera, J. C., Câmara, S. G., \& Berlim, C. S. (2000). Elaboração, desenvolvimento e avaliação de um pro- grama de inserção ocupacional para jovens desempregados. Psicologia: Reflexão e Crítica, 13(1), 189-198.

Sato, L., \& Schmidt, M. L. S. (2004). Psicologia do trabalho e psicologia clínica: um ensaio de articulação focalizando o desemprego. Estudos de Psicologia, 9(2), 365-371.

Schmidt, M. L. S. (2004). Clínica psicológica, trabalho e desemprego: considerações teóricas. Cadernos de Psicologia Social do Trabalho, 7(1), 1-10.

Souza, C. L. C. (2008). Paternidade e desemprego: características do envolvimento paterno e aspectos do relacionamento familiar. Dissertação de Mestrado não publicada, Universidade Vale do Rio dos Sinos, São Leopoldo, Brasil.

Tagliamento, G. (2010). (Não)trabalho e masculidades produzidas em contextos familiares de camadas médias. Psicologia $\mathcal{B}$ Sociedade, 22(2), 345-354.

Terra, C. P., Carvalho, J. A. S., Azevedo, J. E. A., Venezian, L. A., \& Machado, S. B. (2006). Desemprego: discurso e silenciamento - um estudo com clientes de um serviço de aconselhamento psicológico. $\mathrm{Ca}$ dernos de Psicologia Social do Trabalho, 9(1), 33-51.

Urso Júnior, J. (2005). Usando a web em pesquisa psicológica: um estudo sobre stress e coping na busca de emprego on-line. Dissertação de Mestrado não publicada, Universidade de São Paulo, São Paulo, Brasil.

Verardo, L. H. (1999). Desemprego e autogestão. Cadernos de Psicologia Social do Trabalho, 2(1), 55-72.

Vieira, S. M. S. (2002). Desemprego: atribuições de causalidade e valores sociais. Dissertação de Mestrado não publicada, Universidade Católica de Goiás, Goiânia, Brasil.

Zawadzki, B., \& Lazarsfeld, P. F. (1935). The psychological consequences of unemployment. Journal of Social Psychology, 6, 224-251.

Warr, P. (1987). Work, unemployment, and mental health. Oxford: Clarendon Press.

Wilmer, C. (2002). Trabalho e desemprego: uma tentativa de entendimento. Tese de Doutorado não publicada, Pontífica Universidade Católica do Rio de Janeiro, Rio de Janeiro, Brasil. 
